\title{
TEXTOS ESCOLARES CHILENOS Y PERUANOS Y SUS NARRATIVAS SOBRE PARTICIPACIÓN CIUDADANA DURANTE LAS INDEPENDENCIAS NACIONALES. IMPLICANCIAS PARA LA FORMACIÓN CIUDADANA
}

\author{
CHILEAN AND PERUVIAN TEXTBOOKS AND THEIR NARRATIVES ON \\ CITIZENSHIP PARTICIPATION DURING THE NATIONAL INDEPENDENCES. \\ IMPLICATIONS FOR CITIZENSHIP EDUCATION
}

\author{
Eduardo Cavieres-Fernández, Ramón Uzcátegui* ${ }^{* *}$ y Luis Castro Castro ${ }^{* * *}$
}

\begin{abstract}
El objetivo de esta investigación es analizar las narrativas presentadas en los textos escolares chilenos y peruanos (en el periodo entre el 2002 y 2018), acerca de la participación ciudadana desarrollada durante las independencias nacionales. A la luz de sus hallazgos, se discute que si bien presentan elementos que refuerzan aspectos de las narrativas oficiales respecto de la construcción del Estado-nación tanto en Chile como en Perú, centradas en la participación de las elites; también ofrecen contrapuntos referidos a la exclusión de los grupos subalternos. Aquello aporta perspectivas para analizar las concepciones de participación ciudadana contenidas en las directrices acerca de Formación Ciudadana en ambos países, que tienden, en general, a poner más énfasis en la institucionalidad política que en la diversidad social, política y cultural de sus ciudadanías.
\end{abstract}

Palabras claves: Libro de texto, ciudadanía, independencia, política educativa.

This research aims to analyze the narratives in Chilean and Peruvian school textbooks (between 2002-2018) on the citizenship participation developed during their National Independence. Although textbooks present elements reinforcing aspects of the official narratives on the construction of the nation-state in both Chile and Peru, centered on the elites' participation, they also offer counterpoints referring to the exclusion of the subordinate groups. This provides perspectives for analyzing the conceptions on citizenship participation contained in the guidelines on citizenship education in both countries, which tend, in general, to place more emphasis on the political institutions than on the social, political, and cultural diversity of their citizenry.

Key words: Textbooks, citizenship, independence, educational policy.

\section{Introducción}

Así como ha ocurrido en varios países en las últimas décadas, tanto en Chile como en Perú, se han implementado políticas educativas orientadas a la formación ciudadana de los estudiantes, y a su participación como ciudadanos. Aquello es de importancia en la medida que ambos países celebran el Bicentenario de sus Independencias Nacionales; durante estas, además, intercambiaron lazos de colaboración. Debido a la relevancia que tuvieron estas independencias en la conformación de las respectivas ciudadanías, es necesaria la pregunta si su estudio, mediante el currículo escolar, puede igualmente aportar temáticas que refuercen esos otros objetivos, específicamente establecidos para la formación de la ciudadanía, y que no están dirigidos a la formación del pensamiento histórico, más propio de la enseñanza de la historia escolar (van Boxtel y van Drie, 2018). En dicho escenario, los textos escolares aportan perspectivas fundamentales al ofrecer los contenidos que los profesores debiesen utilizar para enseñar los eventos históricos (Navarro y Corredor, 2018). A su vez, estos contenidos suelen ofrecer versiones oficiales de la ciudadanía que merecen ser analizadas por los estudiantes en vistas a su desarrollo como ciudadanos (Sáez-Rosenkranz, 2017; Villalón y Pagès, 2013).

Por tanto, en este estudio revisamos los textos escolares de Chile y Perú, publicados entre el 2002 y 2018, período en el que se han establecido las directrices de la Formación Ciudadana en el currículo, y que contextualizan el estudio que presentamos. Específicamente, nos interesa discutir que, si bien

\footnotetext{
* Universidad de Playa Ancha, Centro de Estudios Avanzados. Viña del Mar, Chile. Correo electrónico: ecavieres-cea@upla.cl

** Universidad Andrés Bello, Chile. Correo electrónico: razktgui@ gmail.com

*** Universidad de Tarapacá, Departamento de Ciencias Históricas y Geográficas. Arica, Chile.

Correo electrónico: lecastro@academicos.uta.cl
} 
las versiones de ciudadanía que emergen de estos textos se centran en el elitismo de los grupos sociales más dominantes de la época y en la institucionalidad política naciente en las sociedades de ambos países, también ofrecen contrapuntos no siempre valorados en la literatura de textos escolares. Ello contribuye a problematizar, incluso, las formas de participación ciudadana propuestas por las políticas de Formación Ciudadana en Chile y Perú, así como proponer perspectivas más robustas en la formación de los futuros ciudadanos. Consecuentemente, el objetivo de este trabajo es analizar las narrativas presentes en los textos escolares chilenos y peruanos acerca de la participación ciudadana desarrollada durante las Independencias Nacionales; y sus implicancias para la formación ciudadana de los estudiantes secundarios hoy.

\section{Políticas de Formación Ciudadana}

Un componente teórico central de este trabajo viene dado por las directrices de la Formación Ciudadana entregadas a nivel escolar en diversos países. Uno de sus objetivos ha sido promover la participación de los jóvenes tanto en la sociedad civil como en relación con las instituciones políticas del Estado para responder ante el aparente aumento de apatía política en la población (Ekman y Amna 2012). Consecuentemente, para revertir esta problemática, estas directrices subrayan la necesidad de orientar la Formación Ciudadana a ayudar a los estudiantes a mantenerse informados respecto de la contingencia social y política, a deliberar en los problemas y temas de la vida social, y a involucrarse en instancias de organización y de servicio en bien de la comunidad (Davies, Flanagan, Hogarth, Mountford y Philpott 2009).

Buena parte de estos conceptos también han sido incluidos en las directrices de Formación Ciudadana tanto en Chile como en Perú, y cuyos alcances deben afectar el conjunto del currículo escolar. Específicamente en Chile, se ha propuesto una Formación Ciudadana escolar que fortalezca el compromiso de los estudiantes a la comunidad nacional en el contexto de un proceso modernizador complejo y ante exigencias globales que demandan una mayor adhesión a los derechos humanos (Ministerio de Educación, 2004; Ministerio de Educación, 2013). Igualmente, en Perú, se insiste en la necesidad de formar ciudadanos participativos que ayuden a la preservación de la unidad nacional frente a ciertos conflictos valóricos que afectan el desarrollo social del país (Ministerio de Educación, 2009). No obstante, en comparación con las directrices chilenas, se enfatiza más la diversidad de la población debido a su mayor sustrato étnico, que requiere, por tanto, el desarrollo de valores interculturales entre los estudiantes (Ministerio de Educación, 2016). En ambos países se subraya que, para alcanzar los objetivos anteriores, se debe formar a ciudadanos que participen dentro los marcos establecidos por el estado de derecho y las instituciones políticas del Estado.

No obstante, en la literatura se han planteado diversas críticas a la comprensión respecto de la participación ciudadana incorporada dentro de estas directrices y que son relevantes para esta investigación (Carr, 2012; Orellana y Muñoz, 2019). En primer lugar, se ha advertido en su carácter Estado-céntrico que da más importancia a la participación política institucional, centrada en mecanismos procedimentales como el sufragio electoral, y que si bien da sustentabilidad al sistema político, relega la participación de los ciudadanos a un rol más pasivo. En segundo lugar, y relacionado con lo anterior, se subraya un énfasis predominante en una forma de participación ciudadana referida fundamentalmente al Estado, y que desconoce las otras maneras de participar que los distintos grupos sociales desarrollan en la esfera más autónoma de la sociedad civil y que, por tanto, son más cercanas a sus intereses políticos y culturales (Mata, 2015; Hervás, 2015).

Otra crítica hacia estas políticas de Formación Ciudadana, aunque no tan desarrollada ni en la literatura chilena ni en la peruana, señala que, aun cuando se promueve la participación en el sistema político, al mismo tiempo, se tiende a desconocer los déficits presentes en los sistemas políticos mismos, y que obstaculizan la participación efectiva de los ciudadanos (Cavieres-Fernández, 2017). En ese sentido, el trabajo de Muñoz-Labraña, Martínez-Rodríguez y Muñoz-Grandón (2016) por las percepciones de estudiantes de último año de enseñanza secundaria en Chile acerca de los políticos, su relación con el poder, y su distancia respecto de los intereses de la ciudadanía, es de relevancia, porque subraya las serias deficiencias en los liderazgos establecidos desde el sistema político. Del mismo modo, Tubino (2006) ha señalado, para el caso peruano, que los liderazgos políticos personalistas han llevado a una cultura política autoritaria con graves consecuencias 
para la democracia, lo que trae consigo desafíos para la formación ciudadana en el país en conexión con las demandas interculturales. Son precisamente estos aspectos problemáticos los que vinculan de manera particular a la Formación Ciudadana con contenidos presentes en el currículo de Historia, en donde dichas temáticas están arraigadas dentro de procesos históricos cuyos puntos de origen se encuentran en las Independencias Nacionales.

\section{El elitismo ciudadano y las ciudadanías subalternas en las Independencias Nacionales}

Consecuentemente, un segundo cuerpo teórico en el que sustentamos este trabajo se refiere a la comprensión respecto del lugar ocupado por las elites en los procesos independentistas y cómo ello influyó en la participación de los grupos subalternos. Este interés ha sido relativamente reciente y ha sido impulsado tanto por los balances adscritos a la celebración de los Bicentenarios como por la necesidad de tener nuevas miradas analíticas considerando el contexto actual de crisis política en gran parte de los países de la región (González Bernaldo, 2015). En este escenario, se han subrayado los complejos alcances sociopolíticos que tuvieron las dinámicas que se desarrollaron entre grupos social y económicamente asimétricos durante la temprana consolidación de las nuevas repúblicas (Chust, 2010; Hébrard y Verdo, 2013; Morán y Aguirre, 2013). Ello ha incluido problematizar que, la comprensión moderna de la sociedad, que instaló la supremacía del individuo como actor social libre desde donde devino la búsqueda de soberanías políticas autónomas, se haya anidado en elites criollas más vinculadas a Europa que a los grupos indígenas y populares locales (Guerra 2009; Villalón y Pagès, 2013; Navarro y Corredor, 2018). No obstante, también se ha podido constatar que las ciudadanías subalternas de la época también avanzaron sus propias reivindicaciones, aunque hayan sido bloqueadas por los nuevos liderazgos. Tal giro temático, formula el problema de la construcción de ciudadanías (en plural) más allá de la mera descripción histórica de los eventos que conformaron las Independencias Nacionales (Chust y Marchena, 2007; Frasquet y Slemian, 2009).

En el caso chileno, la historiografía resalta que, si bien el proceso de la Independencia se basó en ideas ilustradas del bien común, la soberanía popular y la libertad individual, estas representaron más bien a un grupo restringido de la aristocracia local que hizo valer su mayor potestad en virtud de su posicionamiento económico, político y social (Collier, 2012). Más aún, dependiendo de las circunstancias, las diversas facciones de la elite criolla no tan solo usaron indistintamente argumentos a favor de la monarquía, del liberalismo o del republicanismo para asegurar sus intereses, sino que permanentemente se enfrentaron entre ellas para establecer su poder (Cavieres-Figueroa, 2012). Consecuentemente, la participación de los grupos mestizos e indígenas en la formación de la nueva nación fue limitada e instrumental a los intereses de la elite (Pinto y Valdivia, 2009). La historiografía peruana, por su parte, subraya los complejos procesos por los que la elite criolla afianzó su poder partiendo por su apoyo inicial a la monarquía, por ser Perú sede del virreinato, y luego inclinándose por el movimiento independentista para proteger sus privilegios alcanzados en la sociedad colonial (O'Phelan, 2015). Igualmente, señalan las complicaciones que tuvo la elite limeña para alzar un imaginario nacional unitario, a causa de la fragmentación geográfica que derivó de la relación entre Lima y las regiones (Mc Evoy, 2014). Ello supuso un fenómeno canalizado por el caudillismo militar, basado en redes clientelares en permanente conflicto, y que terminó configurando una búsqueda personalista por el control del Estado como consecuencia de la constante inestabilidad política (Velázquez, 2018).

En cuanto a la ciudadanía subalterna, la historiografía chilena ha analizado cómo, tras la Independencia, esta quedó excluida por medio de mecanismos de sufragio establecidos para definir el liderazgo político, y que fueron restringidos a la participación de la elite (Portales, 2011). No obstante, algunos grupos populares tuvieron alguna presencia en cabildos abiertos, mientras otros se opusieron a los marcos institucionales resultantes, ya sea resistiéndose a pelear por la independencia, o emplearse en trabajos productivos de interés para la élite (Salazar, 2001; León, 2011). En tanto, en la historiografía peruana, se señala que, no obstante, el fraccionamiento resultante del caudillismo, los grupos de la elite no tuvieron reparos en generar alianzas con la elite indígena. Esta elite indígena también había desarrollado pretensiones políticas gracias a la diseminación de ideas liberales, que les benefició en materia tributaria y les declaró ciudadanos (Méndez, 2014), y al aprendizaje y empoderamiento que les generó las rebeliones de 
1781 lideradas en Cuzco por Túpac Amaru y en el Alto Perú por los hermanos Katari (O'Phelan, 2012; Walker, 2014). De este modo, aunque de forma limitada, las comunidades indígenas, impulsadas por sus líderes, participaron del proceso Independentista y contaron con mecanismos de discusión propios afines a sus intereses y expectativas (Walker, 2004).

\section{Textos escolares, ciudadanía e independencia nacional}

Los textos escolares constituyen un último foco en esta investigación. Diferentes estudios, desde distintos contextos nacionales, han analizado los contenidos acerca de ciudadanía y participación ciudadana incluidos en los textos escolares señalando críticas que, en general, coinciden con aquellas que reseñamos anteriormente respecto de las actuales directrices de la Formación Ciudadana (Gonzalez, 2017; Soaje de Elías, 2018). Una primera crítica se refiere a las formas de participación que se promueven en estos textos y que se vinculan fundamentalmente al sufragio, y, por tanto, más a las instituciones gubernamentales que a los movimientos políticos que surgen desde la misma ciudadanía (Gonzales, Riedel, Williamson, Avery, Sullivan y Bos, 2004; Ochoa y Vázquez, 2018). Otra crítica se refiere a la limitada atención que se presta al tema de la diversidad en la sociedad, con poco énfasis en el derecho de las minorías para participar más activamente en la sociedad, y los conflictos políticos que derivan de dicha diversidad social (De la Caba, 2006; Almeida y Ramírez, 2011; Faas y Ross, 2012; Canales-Tapia, Fernández-Alister, y Rubio-Poblete, 2018). Desde esta perspectiva, los textos escolares entregarían pocos elementos para que los estudiantes aprendan a participar efectivamente en la sociedad.

De igual manera, los estudios acerca de la enseñanza de hechos históricos en los textos escolares de Historia y Ciencias Sociales también formulan críticas afines. Estos estudios subrayan la función que los distintos sistemas educativos en el mundo les asignan a los textos escolares en la promoción de narrativas nacionalistas oficiales ligadas a la construcción del Estado-Nación y centradas mayoritariamente en la participación de los grupos políticos y sociales de la élite (Araujo y Rodríguez, 2012). Por consiguiente, estos textos también serían excluyentes al desconocer los aportes de los grupos minoritarios; incluyendo los textos chilenos como peruanos (Christianakis, M. y Mora, 2012; Castro, Manzo y Pinto, 2016). Específicamente respecto de estudios pertinentes a los textos escolares y el tratamiento de la Independencia de Chile y Perú, estos han sido marginales, destacándose los trabajos de Vial y Soto (2005), para el caso chileno, y el de Aljovin y Rivera (2005), para el caso peruano. En lo fundamental, estos trabajos coinciden al describir que los textos de ambos países subrayan el rol de la influencia internacional, mediante la propagación de las ideas ilustradas y el protagonismo de las élites criollas y que, por el contrario, hacen escasa referencia a los grupos indígenas y mestizos.

No obstante, si bien esta tendencia descrita en los textos escolares es aún predominante, algunos estudios también subrayan los intentos en algunos países por actualizar los contenidos de los textos escolares de historia incorporando avances historiográficos que permitan matizar los relatos oficiales, así como promover versiones alternativas (Foster, 2012; Sáez-Rosenkranz, 2017). En América Latina, esta mejora favoreció la inclusión de un mayor pluralismo de voces y perspectivas dentro de los textos escolares (Romero, 2004). En línea con lo anterior, el trabajo de Cavieres, Castro, Cavieres y Chaupis (2017) de la Guerra del Pacífico en textos escolares chilenos y peruanos de las últimas décadas, concluye que mientras en ellos se persiste en el relato oficial tradicional de sus respectivos países, asimismo, se ofrecen perspectivas críticas del rol que ocuparon las elites, lo que debiera llevar a pensar en nuevos modos con los que las ciudadanías deberían relacionarse. En este trabajo asumimos esta mirada más matizada para valorizar los aportes de los textos escolares a la formación de ciudadanos.

\section{Método}

\section{Objetivos}

El objetivo de esta investigación es analizar las narrativas presentadas en los textos escolares chilenos y peruanos acerca de la participación ciudadana desarrollada durante las Independencias Nacionales y sus implicancias para la Formación Ciudadana escolar. Por dicha razón, se utiliza una aproximación documental basada en técnicas cualitativas de análisis, en consonancia con estudios pertinentes a textos escolares encontrados en la literatura (Ethier, Lefrançois y Demers, 2013). 


\section{Muestra}

Para la investigación se escogieron 12 textos escolares: 6 chilenos y 6 peruanos, destinados a los estudiantes. Para la selección se abarcó el periodo entre el 2002 y 2018, periodo en que se establecen las normativas específicas en el campo de la Formación Ciudadana en ambos países. No hubo discriminación entre textos escolares destinados a los establecimientos públicos y privados, sino que se privilegió como criterio la disponibilidad para acceder al material. En los casos en que se repitió la misma editorial para dos textos, se eligieron dos versiones completamente distintas y no simplemente nuevas ediciones con los mismos contenidos.

\section{Análisis y reporte de los datos}

En este estudio, los datos propiamente tales están constituidos por las narraciones o descripciones historiográficas escritas contenidas en los textos escolares y que representan los conocimientos oficiales que deben ser transmitidos a los estudiantes. Consecuentemente, se analizaron 414 páginas tomadas del conjunto de los 12 textos escolares estudiados. En esas páginas se revisó toda la narrativa escrita que compone las unidades/capítulos (dependiendo de cada libro) sobre la Independencia Nacional. En general, estos contenidos, aunque varían de texto en texto, incluyen narrativas referidas a las causas, desarrollo y consecuencias de la Independencia.

En el análisis se utilizaron las técnicas cualitativas de la codificación, categorización y tematización, manteniendo la estructura narrativa interna de los textos analizados (Saldaña, 2013). Para ello, se trabajó por separado los textos chilenos y los peruanos. Las narrativas contenidas en los textos fueron reorganizadas de acuerdo con los códigos que se deducen del marco teórico (ie. elitismo, ciudadanía, participación, grupos subalternos, etc.), y otras que emergieron de los textos mismos (personajes, eventos, discursos, etc.). Estos códigos luego fueron agrupados en categorías tales como independencia y nación, participación e independencia, elites y participación, exclusión indígena, entre otras. La triangulación de los datos, para corroborar la noarbitrariedad del análisis realizado, vino dada por la comparación e integración entre sí de las narrativas provenientes de las diferentes fuentes textuales (textos escolares), lo que llevó a la conformación de códigos temáticamente consistentes (Mertens, 2015). Esta triangulación se reforzó, además, con la intervención de dos de los autores en la codificación para garantizar la plausibilidad de la asociación realizada entre los datos y los códigos propuestos.

Finalmente, y con la finalidad de reportar los hallazgos, las categorías que agrupan el mayor número de narrativas con contenidos similares y provenientes de la mayoría de los textos escolares, fueron nuevamente reagrupadas bajo temas que están vinculados a los objetivos de esta investigación. De este modo, el resultado son dos relatos, conformados por citas específicas tomadas de las narrativas presentes en los textos escolares acerca de la Independencia Nacional de Chile y Perú, y rearticuladas en torno a los temas de la élite, grupos subalternos y la participación ciudadana. Para seleccionar estas citas se usó como único criterio el que provinieran de todos los textos escolares para incluir a todas las fuentes en el reporte final. Por último, en los relatos, cada texto escolar es identificado con una sigla propia (Cuadro 1).

Cuadro 1. Textos escolares de Perú y Chile analizados.

\begin{tabular}{lllccc}
\hline \multicolumn{1}{c}{ País } & \multicolumn{1}{c}{ Editorial } & \multicolumn{1}{c}{ Título } & Año & Páginas analizadas & Sigla \\
\hline Perú & Asociación Editorial Hemisferio & Hitos. Ciencias Sociales & 2005 & $214-261$ & $\mathrm{He}$ \\
Perú & Editorial Santillana & Ciencias Sociales 3 & 2008 & $92-131$ & $\mathrm{Sa}$ \\
Perú & Norma & Historia, Geografía y Economía & 2009 & $104-122$ & No \\
Perú & Sociomundo Guevara & Mundo Civilización. Historia, Geografia y Economía. & 2013 & $56-97$ & $\mathrm{Gu}$ \\
Perú & Ediciones SM, S.A. & Historia, Geografía y Economía. 3 ${ }^{\circ}$ de Secundaria & 2014 & $87-106$ & $\mathrm{SM}$ \\
Perú & Norma & Descubre Ciencias Sociales. 3 3 secundaria. & 2016 & $67-119$ & $\mathrm{Nob}$ \\
Chile & Editorial Zig-Zag. & Historia y Ciencias Sociales. 2 ${ }^{\circ}$ medio. & 2002 & $88-104$ & $\mathrm{Zi}$ \\
Chile & Editorial Santillana. & Historia y Ciencias Sociales. 2 ${ }^{\circ}$ Educación media & 2003 & $107-127$ & $\mathrm{Sa}$ \\
Chile & Editorial MN & Historia y Ciencias Sociales. 2 ${ }^{\circ}$ medio & 2006 & $90-115$ & $\mathrm{MN}$ \\
Chile & Editorial Santillana. & Historia y ciencias sociales. 2 ${ }^{\circ}$ Educación media & 2009 & $104-139$ & $\mathrm{Sab}$ \\
Chile & Editorial SM. & Historia, Geografía y Ciencias Sociales. 2 ${ }^{\circ}$ Medio & 2013 & $90-145$ & $\mathrm{SM}$ \\
Chile & Editorial SM. & Historia, Geografía y Ciencias Sociales. 8 8 $^{\circ}$ básico & 2017 & $186-233$ & $\mathrm{SMb}$ \\
\hline
\end{tabular}

Elaboración propia. 


\section{La participación durante la Independencia en los textos escolares chilenos}

\section{La formación del Estado-nación}

En los textos escolares predomina la narrativa que asocia la Independencia Nacional con la conformación de la nación. Según un texto, el estudio de la Independencia permite al escolar conocer cómo "nuestra nación comenzará a dirigir su propio destino" (Sa). Asimismo, un texto expresa que "el proceso de Independencia significó el término de una larga relación política con la Corona española y el desafío de llevar a la realidad el ideal de un Estado nación" (MN). De este modo, la formación del Estado constituye un gran referente para entender a la Independencia, y el modo de participación que le cupo a la ciudadanía: "En el resto de América, los nuevos Estados también experimentaron grandes cambios; la mayoría optó por la creación de repúblicas" (SMb). No obstante, advierte el texto escolar SM, "el grupo de los patriotas tampoco era homogéneo, cuestión que se expresó en las disputas que siguieron a la Independencia y que tenían relación con la construcción del Estado en Chile".

\section{Las elites en el proceso de independencia}

Dentro de la narrativa sobre la Independencia, la "elite", según se desprende de los distintos textos escolares, jugó "un rol central en los procesos de independencia" (SM). De las elites americanas surgieron mucho de los directores del proceso de independencia, "beneficiarios de una educación privilegiada e imbuidos de las ideas ilustradas que llegaban a América y con las que, incluso, se pudieron poner en contacto durante sus estadías en Europa" (SMb). Los textos escolares describen que las elites pasaron de constituir una "elite local" a ser una "aristocracia criolla" en los comienzos de la Independencia, de modo que "combinaron elementos tradicionales y modernos" ( $\mathrm{Zi})$. Por tanto, durante la colonia esta elite progresivamente se fue constituyendo como grupo criollo: "casi todos los oficiales de milicia habían nacido en el país, así, la presencia criolla era abrumadora en los altos cargos de la Iglesia y era muy significativa en la Real Audiencia" (Sab); y como consecuencia "habían logrado infiltrarse en las esferas del poder y de la administración pública" (Sa). Aquello propició la participación de esta élite en la Independencia: "La nueva mentalidad que comenzó a arraigarse en parte de la elite, la cohesión y confianza en sí misma, y el rechazo a las políticas borbónicas que atentaban contra sus intereses jugaron a favor de los cambios que vendrían con posterioridad" (Sab).

En los textos, también se pueden encontrar descripciones respecto de cómo las élites criollas, tras los sucesos de 1808, "aprovecharon el momento y experimentaron un proceso de consolidación local, que las hizo actuar con autonomía respecto de los funcionarios imperiales" (SMb). Consecuentemente, se "consolidó la necesidad de formar también en Chile nuestra primera Junta de Gobierno" (Zi), que se instala en Santiago y que posibilita que "la elite criolla pasara a ocupar cargos de importancia en el aparato administrativo, hasta ese momento en manos de funcionarios españoles" (SM). Entre sus funciones estuvo "el ocuparse de las tareas de gobierno, hasta que se procediese a la elección de un Congreso" (MN). De igual forma "La Primera Junta de Gobierno convocó a un Congreso Nacional de delegados de todas las provincias y ciudades más importantes, con el objetivo de conformar un Gobierno Nacional" (SM); así como favorecer el uso de la imprenta para transmitir las ideas independentistas: "comenzó a publicarse el Monitor Araucano, periódico que sucedió a la Aurora de Chile" (SM 2013). No obstante, a lo largo de todo el proceso fueron constantes las pugnas de poder y de conflicto entre estos grupos de la elite: "surgieron entre los criollos diferentes bandos políticos, que manifestaron sus preferencias proponiendo distintas formas de gobernar. Algunos líderes independentistas encabezaron tendencias políticas: fuesen como caudillos, dirigentes políticos o militares con poder de facto" (MN).

\section{Mundo popular y sectores indígenas}

La élite criolla procuró atraer a los sectores populares por medio de la difusión de ideas, especialmente mediante catecismos políticos que "planteaban a sus lectores preguntas y respuestas que expresaran el apoyo a las ideas independentistas y las nuevas autoridades" (MN). No obstante, la participación del mundo popular mestizo y de los sectores indígenas fue limitada, "ocupándose principalmente de engrosar los batallones y mantener un nivel aceptable de la producción económica del país" (SMb). De manera particular, la participación popular se asoció al guerrillero criollo Manuel 
Rodríguez quien "supo capitalizar estos sentimientos, que también emergían entre algunos grupos de los sectores populares, y organizó las montoneras que hostilizaron y dispersaron a las fuerzas realistas" (Sa). No obstante, el logro de la independencia "no significó el acceso a la participación política para la gran mayoría de la población, que quedó durante todo el período excluida del sistema de elección de las autoridades" (MN).

Consiguientemente, los textos escolares señalan que la Independencia Nacional no trajo grandes cambios a nivel de la estructura social: "Chile continúa siendo una sociedad rural: casi un $80 \%$ de la población vivía en los campos, marginada de los procesos políticos y de los distintos planteamientos ideológicos que se expresaban en el país" (Zi). Tras la independencia, los grupos populares "no vieron modificada sustancialmente su forma de vida" (SM). La independencia se desarrolló "aún cuando la mayoría de la población de estratos bajo permanecía ajena a los motivos del conflicto" (Sab). Más aún, la guerra de independencia, "llevó a la amplia destrucción de las zonas de conflicto y al desplazamiento de poblaciones mapuches y de mestizos pobres, grupos que se vieron involucrados a su vez en los combates en uno y otro de los bandos" (MN). Como concluye un texto escolar, al finalizar la independencia "la suerte que corrían los miembros de los grupos populares poco importaba a la élite" (SMb).

\section{La participación durante la Independencia en los textos escolares peruanos}

\section{La formación del Estado - nación}

Los textos escolares resaltan el valor de la Independencia, "fundamental en nuestra historia, pues es la "partida de nacimiento" del Perú como República" (Gu). En ello, un texto escolar, resalta la contribución de los propios peruanos de la época: "Los peruanos no permanecimos indiferentes al proceso de emancipación que se operaba en otras regiones de América Latina. Tratamos y buscamos materializar nuestra independencia; hombres y figuras ilustres lucharon por conseguirla" (He). No obstante, por ser Perú sede del virreinato y concentrar el poderío español en la región, también resultó del "conflicto entre los sectores que buscaban independizarse de España (de) aquellos otros que deseaban mantener el dominio español. Como resultado de este enfrentamiento, se conformaría nuestro Estado" $(\mathrm{Gu})$. También la Independencia reflejó la tensión inicial entre la capital y las provincias; de hecho, "las rebeliones no se produjeron en Lima sino en regiones" (No).

\section{Las elites en el proceso de independencia}

Los textos escolares coinciden en que a partir de 1810, "la emancipación del Perú fue impulsada, principalmente, por los sectores criollos" (Sa), que inicialmente conformaron dos bloques, el primero "representado por los que mantenían la adhesión a la política colonial española; pero exigían cambios y reformas en las autoridades de gobernar y en las leyes"; y el segundo, por círculos intelectuales agrupados en la Sociedad de Amantes del País y el Mercurio Peruano que anhelaban la autonomía (He). Durante la primera etapa del movimiento independentista predominó el primer grupo, particularmente en Lima, en donde "estaba el grupo de comerciantes más ricos del virreinato peruano y debía su posición al monopolio comercial que les garantizaba grandes dividendos económicos" (No). No obstante, a medida que se fueron consolidando las Independencias a nivel continental, "no hay duda de que los principales líderes en la etapa final de la independencia fueron criollos" (Gu), pero, como continúa el mismo texto escolar, las diferencias entre los criollos persistieron: "algunos grupos apoyaron los cambios (...) mientras en otros lugares se miraba con recelo el poder que los criollos limeños podían tener con la Independencia (...) criollos costeños, criollos del interior (...) también calculaban los que les podría ser beneficioso".

En cuanto a las formas de participación de las elites durante la Independencia, desde un comienzo estas buscaron asociarse: "La primera forma de conspiración se dio en las tertulias de profesores y alumnos" (Sa). Igualmente, durante una primera etapa, algunos criollos lideraron revueltas en provincias, y en Lima buscaron establecer una Junta de Gobierno con autonomía de España; pero estos esfuerzos fueron duramente reprimidos por los españoles: "Aquí no se formó una Junta de Gobierno, no por falta de inquietud libertaria de los criollos (...), sino por la férrea autoridad del virrey" $(\mathrm{He})$. No obstante, aprovechando una serie de libertades civiles que se fueron concediendo, los criollos pudieron hacer circular una serie de periódicos a "través de cuyas páginas se difundieron los ideales 
de libertad, al tiempo que se preparaban los espíritus para conseguir la emancipación política con respecto a España” (He). Finalmente, serán los criollos los que asumirán el protagonismo a partir de la declaración de la Independencia del Perú, proclamada en Cabildo abierto, pero al que "no fueron citados todos los ciudadanos de Lima; (sino) mayormente (los) viejos representantes del colonialismo" (Nob). También serán los criollos los que optarán por el sistema republicano para organizar al país "sobre la base de las ideas de la autonomía política y económica y el concepto de ciudadanía" (Sa). En el texto Sa se destacan las continuas divisiones entre los grupos criollos reflejando su "actitud ambigua frente al cambio de sistema, pues apoyaban distintas causas según la oportunidad”.

\section{Mundo popular y sectores indígenas}

De acuerdo con un texto escolar, hacia fines de la Colonia, "La distribución de esta población fue bastante desigual. Así los negros, las castas y los españoles residían fundamentalmente en las ciudades, mientras que la población indígena se encontraba mayoritariamente en las zonas-rurales de la sierra y de la costa" $(\mathrm{Gu})$. El reconocimiento otorgado por parte de los españoles a la nobleza indígena, a la que le otorgó "privilegios y comodidades", le dio igualmente el poder para liderar las primeras rebeliones en el virreinato del Perú $(\mathrm{Gu})$. De allí que un texto afirme que "la rebelión de Túpac Amaru es considerada por muchos el principal antecedente de la independencia del Perú" (Nob). Sin embargo, el aplastamiento de estas rebeliones significó que los indígenas perdieran sus "liderazgos propios" y, por tanto, que sus intereses "quedarán de lado", siendo reemplazados por los intereses de los criollos quienes comenzaron a liderar las luchas separatistas $(\mathrm{Gu})$.

A partir de 1810, la participación de los grupos populares quedó restringida a "numerosos grupos de montoneros, guerrillas indígenas y populares" (No). Así, un texto explica, "el movimiento independentista utilizó las expectativas de la población esclava en torno a la abolición. Ambos ejércitos, el patriota y realista, usaron estas expectativas para proveerse de soldados" (Sa). Si bien al final del proceso, se hicieron algunas concesiones al mundo popular y sectores indígenas, se "suprimió el tributo indígena y la servidumbre personal" (SM); en lo fundamental, "a pesar de los terribles efectos de la guerra sobre la economía y el aparato estatal, la estructura social peruana siguió siendo similar a la de la época colonial: los blancos, básicamente criollos, siguieron en la cúspide de la pirámide social" (Sa). Más aún, como concluye el texto, se excluyeron a "los pordioseros, los sirvientes y esclavos, las mujeres y los niños, a quienes se consideraba privados de independencia económica y de pensamiento" (Sa).

\section{Discusión}

Los relatos presentados al modo de hallazgos, no son meros resúmenes de los contenidos presentados en los textos escolares, sino que constituyen una lectura posible, a partir de la reorganización interpretativa de sus narrativas en torno a los temas de las elites y los grupos subalternos durante la Independencia Nacional, de cómo presentan la temática de la participación ciudadana en dicho proceso. Como consecuencia, estos relatos resaltan varios aspectos. En primer lugar, destacan similitudes importantes entre las principales narrativas contenidas tanto en los textos escolares de Chile y Perú para describir los procesos de la Independencia; lo que justifica el ser estudiadas simultáneamente. De igual modo, comparten elementos característicos de las versiones oficiales que han buscado transmitir una versión única de cómo se han configurado las naciones (Foster, 2012). Entre ellos, destaca como elemento fundacional de las Independencias el que hayan respondido a procesos liderados fundamentalmente por las elites criollas locales cuya ubicación dentro de la estructura social y geográfica les permitió concentrar el poder militar y político necesario para reaccionar a la crisis de la monarquía, y avanzar sus particulares intereses y comprensiones respecto de cómo construir los nuevos Estados autónomos.

No obstante, de la lectura de estos relatos, no concluimos necesariamente que estos textos escolares tengan como intencionalidad explícita legitimar o promover que los Estados deban ser construidos principalmente por las elites. Por cierto, es evidente que, dependiendo de las epistemologías que se ocupen para analizarlos (León, 2011), los contenidos de estos textos podrían ser más críticos frente a las relaciones jerarquizadas y centradas en los personajes de la elite criolla que sustentaron las Independencias Nacionales. Sin embargo, aunque estos textos escolares describen más que analizan, también incorporan información respecto del lugar 
de los grupos subalternos, y sobre las acciones que llevaron adelante los grupos dirigentes para generar exclusión social y política. Aquello puede contribuir significativamente a que, al ser estudiados, el carácter elítico de la independencia no se interprete como un hecho inexorable dadas las circunstancias de la época, sino que, por el contrario, se comprenda como resultado del arbitrio de un determinado grupo social que podría haber buscado mejores alternativas para afianzar lazos de mayor libertad y justicia social en los países nacientes.

\section{Independencia y participación ciudadana}

El foco puesto en el comportamiento de las elites en las narrativas de los textos escolares chilenos y peruanos analizados, ciertamente influye en el modo de entender la participación ciudadana que se desarrolló durante las Independencias Nacionales. En la descripción recogida, se prefiguran muchos aspectos que, además, fueron caracterizando la participación ciudadana liberal posterior sustentada en la formación intelectual de los grupos dirigentes, bajo la fuerte influencia de ideas provenientes de naciones con más desarrollo político y económico, y que asumieron, dentro de las instituciones del Estado, la toma de decisiones respecto de los asuntos públicos. Estos relatos también aportan elementos que contribuyen a lecturas más problematizadoras, tales como las tensiones y conflictos al interior mismo de los grupos criollos y que derivaron en formas de participación centradas en el ascenso a los nuevos puestos de poder que fueron surgiendo a medida que se consolidaban las nuevas repúblicas.

Esta narrativa en los textos escolares estudiados, que resalta la predominancia de las elites, también alude a la exclusión que sufrieron los demás grupos sociales, mestizos e indígenas, tal como se ha ido explicitando en la historiografía citada en el marco conceptual (Portales, 2011). De este modo, estos textos escolares describen cómo estos grupos quedaron remitidos fundamentalmente a la participación armada en el conflicto bélico y, por tanto, con ninguna injerencia en las decisiones políticas de las repúblicas emergentes. Más aún, de los textos escolares es posible colegir de parte de las elites una intencionalidad expresa de defender sus intereses a costa de reafirmar las jerarquías raciales y sociales existentes en la época; un aspecto particularmente subrayado en los textos peruanos. Este reconocimiento constituye un avance innegable respecto de la función tradicionalmente asignada a los textos escolares de transmitir narrativas nacionales lineales centradas en personajes-héroes que escapan a cualquier cuestionamiento respecto de su liderazgo. No obstante, en su descripción por la falta de participación ciudadana de los grupos subalternos, los textos no integran mayormente aspectos de los análisis historiográficos recientes que han subrayado otras formas de participación que existieron al margen de la nueva institucionalidad emergente tal como lo reseñamos igualmente en el marco conceptual (Salazar, 2001). Esta ausencia podría llevar al equívoco de equiparar exclusión con pasividad, y con ello, marginalizar aún más los aportes que los grupos excluidos pueden hacer a la construcción democrática de los países.

\section{Textos escolares, participación y formación ciudadana}

En el contexto de este trabajo, las descripciones que aportan los textos escolares de la participación ciudadana que se desarrolló en las Independencias Nacionales, no tan solo influye en los aprendizajes historiográficos de los estudiantes -y que no son foco de este trabajo- sino que tienen implicancias a ser discutidas a la luz de las directrices sobre Formación Ciudadana en Chile y el Perú, y reseñadas en el marco conceptual. En lo fundamental, frente a las concepciones acerca de la participación ciudadana contenidas en estas directrices, sustentadas en modelos de democracia sostenidos sobre la base de un sistemas de partidos políticos con idearios ideológicos que devienen del liberalismo republicano, y mecanismos eleccionarios que han favorecido la conformación de elites; la narrativa sobre la Independencia Nacional, como momento fundacional en ambos países, posibilita la discusión acerca de los avances que dicho elitismo ha permitido en la construcción de la nación, en medio de contingencias nacionales e internacionales; y acerca de los liderazgos políticos que se han llevado adelante en medio de serias adversidades y conflictos. Es evidente que aquello es pertinente a las temáticas sobre participación en las actuales instituciones políticas del país promovidas desde las políticas sobre Formación Ciudadana.

Sin embargo, también es posible que estas narrativas presentadas en los textos escolares, en la medida que recogen muchas de las versiones oficiales acerca de la construcción del Estado-nación, 
refuercen comprensiones que reducen la participación ciudadana meramente al elitismo económico y social, y a la institucionalidad política, tal como lo criticamos en el marco conceptual (Carr, 2012). Consiguientemente, una lectura de los contenidos sobre la Independencia Nacional en los textos escolares, a la luz de las directrices sobre Formación Ciudadana, podría llevar a concluir que los grandes procesos de conformación de las naciones resultaron de la participación de pequeños grupos con el bagaje cultural, económico y social para dirigir al resto de la población hacia finalidades establecidas por ellos. Desde la perspectiva teórica que hemos adoptado en este trabajo, aquello entraña una mirada limitada respecto al derecho de participación que cabe a los diversos grupos sociales dentro de una sociedad democrática.

No obstante, los textos escolares tanto chilenos como peruanos también incorporan elementos que permiten problematizar dicha comprensión de la participación ciudadana. Por cierto, la mención de los conflictos entre los grupos de elite, igualmente considerados en las historiografías tradicionales sobre las independencias, advierten de los peligros de esta forma de participación que ha entrañado luchas de poder entre estos grupos, y ha llevado a prácticas con profundas implicancias éticas y legales (por ejemplo, el abuso de poder, la violencia política o la corrupción). De igual forma, el reconocimiento por parte de los textos escolares de que las elites excluyeron a buena parte de la población local de la toma de decisiones en el proceso independentista, contribuye a discusiones respecto de la falta de diversidad social, cultural y económica entre quienes acceden a los espacios de poder. Más aún, a partir de la pregunta respecto de si las independencias nacionales pudieron haber sido más inclusivas y haber valorizado otras formas de participación ciudadana fuera de la institucionalidad del Estado naciente, los textos pueden servir como punto de partida para reflexionar, desde la perspectiva narrativa de la historia, sobre posibles relatos de cómo los grupos marginados pueden mover a las élites a darles mayores espacios de participación y a respetar sus propias formas de participar.

\section{Conclusión}

El objetivo de esta investigación era analizar las narrativas presentes en los textos escolares chilenos y peruanos acerca de la participación ciudadana desarrollada durante las Independencias Nacionales; y sus implicancias para la Formación Ciudadana escolar. A la luz de sus hallazgos, se concluye que estos textos, si bien presentan elementos que refuerzan aspectos de las narrativas oficiales acerca de la construcción del Estado-nación tanto en Chile como en el Perú, centradas en la participación de las elites, también ofrecen contrapuntos referidos a la exclusión de los grupos subalternos que coinciden con los aportes entregados por la historiografía más reciente reseñada en el marco teórico. Aquello, a su vez, aporta perspectivas para analizar las concepciones de la participación ciudadana contenidas en las directrices respecto de Formación Ciudadana en ambos países, que tienden, en general, a poner más énfasis en la institucionalidad política que en la diversidad social, política y cultural de sus ciudadanías; aunque este último aspecto esté más resaltado en las directrices peruanas.

Es evidente que estas conclusiones no debieran opacar los análisis que existen dentro del campo de la enseñanza de la historia, en el que se ha discutido igualmente la relación entre los contenidos de enseñanza de la historia con finalidades de formación ciudadana (Longstreet, 1996; González Amorena y Henríquez Vásquez, 2003; Tutiaux-Guillon, 2003). En efecto, la historiografía ha desarrollado un interés central por las formas de ciudadanía que se desplegaron desde el proceso mismo de las independencias, y cuyo trasvasije al conocimiento escolar, mediado por los textos escolares, requiere de un saber de la historia de la ciudadanía articulado tanto por la cuestión de la conciencia histórica como por la discusión de qué se entiende por ciudadanía (Pagès, 2003; Peyrou, 2012). Ello exige a su vez implementar estrategias de enseñanza-aprendizaje en torno a la difícil triangulación entre el pasado como "objeto de trasmisión", el presente como escenario de la convivencia ciudadana y el futuro como construcción democrática (López Atxurra, 2007). No obstante, dicha complejidad ha justificado, más bien, incluso, el separar en el currículo más tajantemente, el ámbito de la enseñanza de la historia con el de la Formación Ciudadana más centrada en temáticas de la institucionalidad política actual (Mardones, 2015). En ese contexto, el presente estudio, ayuda a mantener conectados ambos campos al proponer vinculaciones por medio de los textos escolares, aunque estudios a futuro deberán considerar con mayor atención la compatibilidad, o no, por ejemplo, entre objetivos de la enseñanza de la historia con aquellos de la formación ciudadana, al 
menos, tal como han sido definidos por las directrices curriculares más amplia del Estado.

En definitiva, este trabajo valoriza el aporte que los textos escolares puedan estar entregando, a pesar de sus limitaciones, al presentar narrativas más balanceadas respecto de los procesos históricos que conformaron el conjunto de las ciudadanías en ambos países. En ese sentido constituyen un recurso a considerar al momento de ampliar los marcos curriculares oficiales dentro de los cuales se propone formar a los estudiantes a participar ciudadanamente. Por cierto, aquello dependerá de profesores y estudiantes, y de las lecturas que hagan de estas narrativas para favorecer la discusión y la reflexión crítica. La celebración del Bicentenario de las independencias en ambos países parece un momento particularmente oportuno para ello, ante los desafíos de continuar conformando sociedades más inclusivas que puedan, además, integrarse entre sí, a partir de sus narrativas históricas compartidas, en vistas a la construcción de una región más democrática.

\section{Agradecimientos}

Esta investigación ha sido realizada gracias al financiamiento de FONDECYT (Fondo Nacional de Desarrollo Científico y Tecnológico) proyecto n. $\mathrm{N}^{\circ} 1180475$.

\section{Referencias Citadas}

Aljovin, C. y Rivera, V.

2005 Perú. En Los procesos independentistas iberoamericanos en los manuales de historia, editado por R. Valls, pp. 111- 129, OEI-Fundación MAPFRE, Madrid.

Almeida, G., y Ramírez. T.

2011 "El afrocolombiano en los textos escolares colombianos. Análisis de ilustraciones en tres textos de ciencias sociales de básica primaria". Actualidades Pedagógicas, 57: 213-234.

Araújo, M. y Rodríguez, M.

2012 "History textbooks, racism and the critique of Eurocentrism: beyond rectification or compensation". Ethnic and Racial Studies, 7: 1266-1286.

Canales-Tapia, P., Fernández-Alister, M., y Rubio-Poblete, A. 2018 "Textos escolares de Historia: la reproducción del racismo contra los pueblos indígenas en Chile". Revista Austral de Ciencias Sociales, 34: 153-167.

Carr, P.

2012 "Democracy, critical pedagogy and the education of educators". En: Can educators make a difference? Experimenting with, and experiencing, democracy in education, editado por P. Carr, D. Zyngier, y M. Pruyn, pp. 23-56, NC: Information Age, Charlotte.

Castro, L., Manzo, L. y Pinto, C.

2016 "Las imágenes femeninas en los textos escolares chilenos: revisión analítica en un escenario de cambios (1992-2012)". Revista de Pedagogía, 37: 207-227.

Cavieres-Fernández, E.

2017 "Teacher counter stories to a citizenship education mega policy narrative. Preparing for citizenship in Chile". Journal of Curriculum Studies, 49: 414-436.

Cavieres-Fernández, E; Castro, L.; Cavieres Figueroa, E. y Chaupis, J.

2017 “Textos escolares y la guerra del pacífico: ¿obstáculos o instrumentos para la integración de chilenos y peruanos?". Revista de Pedagogía, 38: 53-79.

Cavieres Figueroa, E.

2012 Sobre la independencia en Chile. El fin del antiguo régimen y los orígenes de la representación moderna. Ediciones Universitarias de Valparaíso, Valparaíso.
Christianakis, M. y Mora, R.

2012 "E pluribus unum: Elementary school narratives and the making of national identity". En The new politics of the textbook. Problematizing the portrayal of marginalized groups in textbooks, editado por H. Hickman y B. Porfilio, pp. 107-125, Sense Publishers, Rotterdam.

Chust, M. (edit.).

2010 Las independencias Iberoamericanas en su laberinto. Controversias, cuestiones, interpretaciones. Universitat de València, Valencia, España.

Chust, M. y Marchena, J. (eds.).

2007 Las armas de la nación. Independencias y ciudadanías en Hispanoamérica (1750-1850). Iberoamericana Vervuert, Madrid-Fankfort.

Collier, $\mathrm{S}$.

2012 Ideas y política de la independencia chilena 1808-1833. Fondo de Cultura Económica, México D.F

Davies, I.; Flanagan, B.; Hogarth, S.; Mountford, P. y Philpott, J. 2009 "Asking questions about participation". Education, Citizenship and Social Justice, 4: 25-39.

De la Caba, M. y López R.

2006 "Democratic citizenship in textbooks in Spanish primary curriculum". Journal of Curriculum Studies, 38: 205-228.

Ekman, J., y Amna, E.

2012 "Political participation and civic engagement: Towards a new typology". Human Affairs, 22: 283-300.

Éthier, M., Lefrançois, D. y Demers, S.

2013 "An analysis of historical agency in Québec history textbooks". Education, Citizenship and Social Justice, 8: 119-133.

Faas, D. y Ross, W.

2012 "Identity, diversity and citizenship: A critical analysis of textbooks and curricula in Irish schools". International Sociology, 27: 574-591.

Foster, S.

2012 "Re-thinking history textbooks in a globalized world". En History education and the construction of national identities, editado por M. Carretero; M. Asensio, y M. Rodríguez- Moneo, pp. 49-62, Information Age Publishing, Inc, London. 
Frasquet, I. y Slemian, A. (eds.).

2009 De las independencias iberoamericanas a los estados nacionales, (1810-1850). 200 años de historia. Iberoamericana Vervuert, Madrid-Fankfort.

González, F. y Gárate, C.

2017 "El aprendizaje histórico en la educación secundaria. Jóvenes chilenos y conciencia histórica". Diálogo Andino, 53: 73-85

Gonzales, M.; Riedel, E.; Williamson, I.; Avery, P.; Sullivan, J. y Bos, A.

2004 "Variations of citizenship education: A content analysis of rights, obligations, and participation concepts in high school civic textbooks". Theory and Research in Social Education, 32: 301-325.

González, M.P.

2017 "Los saberes históricos escolares como construcción situada y singular". Revista Diálogo Andino, 53: 45-57.

González Amorena, M.P. y Henríquez Vásquez, R.

2003 "Conciencia histórica y cultura material: aproximaciones desde la enseñanza de la historia". In El patrimonio y la didáctica de las ciencias sociales, coordinado por $\mathrm{E}$. Ballesteros, C. Fernández, J.A. Molina y P. Moreno, pp. 113120. Asociación Universitaria de Profesores de Didáctica de las Ciencias Sociales, Universidad de Castilla-La Mancha, Cuenca, España.

González Bernaldo, P.

2015 Independencias Iberoamericanas. Nuevos problemas y aproximaciones. Fondo de Cultura Económica, Buenos Aires, Argentina.

Guerra, F.

2009 Modernidad e independencias. Ensayos sobre las revoluciones hispánicas. Encuentro, Madrid.

Hébrard, V. y Verdo, G. (eds.).

2013 Las independencias hispanoamericanas. Un objeto de historia. Casa de Velázquez, Madrid.

Hervás, D.A.

2015 "Ciudadanía, educación y complejidad: miradas desde la ecopedagogía”. Revista Diálogo Andino, 47: 95-104.

León, L.

2011 Ni patriotas ni realistas. El bajo pueblo durante la independencia de Chile 1810-1822. Centro de Investigaciones Diego Barros Arana, Santiago de Chile.

Longstreet, W.S.

1996 "Alternative futures and the social studies". En Handbook on Teaching Social Issues, editado por R. Evans y D. Saxe, pp.317-326. National Council for the Social Studies, Washington, USA.

López Atxurra, R.

2007 "La enseñanza de la historia y el pacto de ciudadanía: interrogantes y problemas". In Historia e identidades nacionales. Hacia un pacto entre la ciudadanía vasca, editado por M. Arbaiza y P. Perez Fuentes, pp. 166-187. Servicios Redaccionales Bilbainos, Bilbao, España.

Mardones, R.

2015 El paradigma de la educación ciudadana en Chile: una política pública inconclusa. En Aprendizaje de la ciudadanía. Contextos, experiencias y resultados, editado por C. Cox y J. Castillo, pp. 145-175. Ediciones Universidad Católica de Chile, Santiago, Chile.

Mata, P.

2015 ““'Dos ojos o más’: liderazgos colectivos en el marco de la acción de una ciudadanía transformadora". Revista Diálogo Andino, 47: 115-121.
Mc Evoy, C.

2014 "La vida política". In Perú. La construcción nacional, Tomo 2, editado por C. Contreras, pp. 35-99, Fundación MAPFRE, Taurus, Lima.

Méndez, C.

2014 La república plebeya. Huanta, formación del Estado peruano, 1820-1850. Instituto de Estudios Peruanos, Lima.

Mertens, D. M.

2015 Research and evaluation in education and psychology: Integrating diversity with quantitative, qualitative, and mixed methods. Sage publications, California.

Ministerio de Educación.

2004 Formación ciudadana. Actividades de apoyo para el profesor. Historia y ciencias sociales. $1^{\circ}$ básico a $4^{\circ}$ medio. Gobierno de Chile, Santiago de Chile.

Ministerio de Educación.

2009 Diseño curricular nacional de Educación Básica Regular. Ministerio de Educación, Lima

Ministerio de Educación.

2013 Orientaciones técnicas y guiones didácticos para fortalecer la formación ciudadana $7^{\circ}$ básico a $4^{\circ}$ medio. Ministerio de Educación/División de Educación General, Santiago de Chile.

Ministerio de Educación.

2016 Educación básica regular. Programa curricular de educación secundaria. Ministerio de Educación, Lima.

Morán, D. y Aguirre, M.

2013 La plebe en armas. La participación popular en las guerras de independencia. Fondo Editorial Universidad Peruana Simón Bolívar, Lima, Perú.

Muñoz-Labraña, Carlos y Martínez-Rodríguez, Rosendo y

Muñoz-Grandón, Carlos.

2016 "Percepciones del estudiantado sobre la política, los partidos políticos y las personas dedicadas a la política al finalizar la educación secundaria en Chile". Revista Electrónica Educare, 20: 1-16.

Navarro-Roldán, C. y Corredor-Aristizábal

2018 "Comunalidades entre las narrativas históricas de estudiantes y textos escolares: un análisis cualitativo". Revista Colombiana de Educación, 75: 119-138.

O'Phelan, S.

2012 Un siglo de rebeliones anticoloniales. Perú y Bolivia 1700-1783. IEP, IFEA, Lima, Perú.

O'Phelan, S.

2015 La independencia en los Andes. Una historia conectada. Fondo Editorial del Congreso del Perú, Lima.

Ochoa Cervantes, Azucena de la Concepción, y Vázquez Bravo, Felicia

2018 "Análisis del concepto de participación en los libros de formación cívica y ética de $4^{\circ}, 5^{\circ}$ y $6^{\circ}$ grado". Sinéctica: 50.

Orellana Fonseca, C. y Muñoz Labraña, C.

2019 "Escuela y Formación ciudadana: Concepciones de ciudadanía, formación ciudadana y del rol de la escuela". Revista Electrónica Interuniversitaria de Formación del Profesorado, 22: 137149.

Pagès, J.

2003 "Ciudadanía y enseñanza de la historia". Reseñas de Enseñanza de la Historia 1: 11-42.

Peyrou, F.

2002 "Ciudadanía e Historia. En torno a la ciudadanía". Historia Social 42: 145-166. 
Pinto, J. y Valdivia, V.

2009 ¿chilenos todos? La construcción social de la nación (1810-1840). LOM, Santiago de Chile.

Portales, F.

2011 Los mitos de la democracia chilena. Desde la conquista hasta 1925. Catalonia, Santiago de Chile.

Romero, L.

2004 La Argentina en la escuela. La idea de nación en los textos escolares. Siglo Veintiuno Editores, Buenos Aires.

Sáez-Rosenkranz, Isidora.

2017 "La enseñanza de la historia en los libros de texto de educación básica en Chile". Enseñanza de las Ciencias Sociales, 16: 27-40.

Salazar, G.

2011 Construcción de Estado en Chile (1800-1837). Democracia de los "pueblos". Militarismo ciudadano. Golpismo oligárquico. Editorial Sudamericana, Santiago de Chile.

Saldaña, J.

2013 The coding manual for qualitative researchers. SAGE, California.

Soaje de Elías, R.

2018 "Textos escolares: consideraciones didácticas". Educación y Educadores: 21: 73-92.

Tubino, F.

2006 "Perú: educación, interculturalidad y buen gobierno". Revista Futuros, 4: 1-7.
Tutiaux-Guillon, N.

2003 "L'histoire enseignée entre coutume disciplinaire et formation de la conscience historique: l'exemple français". In Identités, mémoires, conscience historique, editado por N. Tutiaux-Guillon y D. Nourrisson, pp. 27-41. Université de Saint-Étienne, Saint-Étienne, Francia.

Velásquez, D.

2018 "Ejército, política y sociedad en el Perú, 1821-1879". Trashumante. Revista Americana de Historia Social, 12: 142-164.

Vial, S. y Soto, A.

2005 "Chile". En Los procesos independentistas iberoamericanos en los manuales de historia. Vol. 2, editado por: R. Valls, pp. 81-115, OEI-Fundación MAPFRE, Madrid.

Walker, C.

2004 De Tupac Amaru a Gamarra. Cusco y la formación del Perú republicano 1780-1840. CBC, Cusco.

Walker, C.

2014 La rebelión de Tupac Amaru. IEP, Lima, Perú.

Villalón, G.; Pagès Blanch, J.

2013 “QQuién protagoniza y cómo la historia escolar? La enseñanza de la historia de los otros y las otras en los textos de estudio de Historia de Chile de educación primaria". Clio \& Asociados, 17: 119-136. 